\title{
A Free Fatty Acid Receptor Agonist Inducing Autophagy in HT-29 Cells by Downregulating The AKT/mTOR Signaling Pathway in Fibrin Gel Matrices
}

Elham Hoveizi ( $\nabla$ e.hoveizi@scu.ac.ir)

Shahid Chamran University of Ahvaz https://orcid.org/0000-0002-3285-5682

Behnoosh Rafienia

Shahid Chamran University of Ahvaz

Ali Shahriari

Shahid Chamran University of Ahvaz

\section{Research Article}

Keywords: Autophagy, Akt/mTOR pathway, GW9508, Molecular docking, Oxidative stress

Posted Date: July 7th, 2021

DOl: https://doi.org/10.21203/rs.3.rs-662911/v1

License: (c) (i) This work is licensed under a Creative Commons Attribution 4.0 International License.

Read Full License 


\section{Abstract \\ Objective}

GW9508, a free fatty acid receptor agonist acts in a G-coupled Protein Receptor 40 (GPR40)-dependent pathway. Here, we investigated the induction of stress oxidative and autophagy by GW9508 in the human colorectal cancer cell line (HT-29) and the crosstalk between autophagy and apoptotic in HT-29 cells.

\section{Methods}

HT-29 was treated with GW9508 at a concentrations range of $50-500 \mu \mathrm{M}$ in fibrin gel. Cell viability was investigated using an MTT assay. Induction of autophagy and apoptosis was assessed through Western blotting for associated proteins, acridine orange staining, MDC staining, qRT-PCR, and electron microscopy. Also, we estimated the molecular interactions between GW9805 and some markers through molecular docking.

\section{Results}

GW9508 inhibited HT-29 cell proliferation, induced apoptosis, and resulted in autophagy. The induced autophagy in cells was confirmed by the observation of autophagosomes, the presence of autophagy markers, including beclin-1, LC3, AMPK, and lack expression of mTOR and AKT. Moreover, GW9508 treatment significantly increased the expression of catalase and Superoxide dismutase (SOD) in cells.

\section{Discussion}

Our results indicated that GW9508 could induce autophagy by inhibiting the Akt/mTOR in HT-29. Hence, GW9508 is suggested as a novel anti-cancer reagent.

\section{Introduction}

Colorectal cancer is the third most frequent malignant disease and the fourth avoidable cause of death (cancer-related) around the world[1]. Despite improvements in the control and treatment of some cancers, controlling patients with colorectal cancer is very unpredictable. Therefore, it is necessary to improve new agents for this banana cancer. Certainly, lifestyle and nutrition play a key role in preventing cancer[2, 3].

Based on a previous study, fatty acids can be considered as an anti-cancer agent by inducing cell death in tumor cells[4,5]. Currently, they are recognized as a therapeutic policy for colorectal cancer. For example, Fauser et al. reported that butyrate could induce apoptosis in HT-29 cells and inhibited invasive potential and proliferation of these cells. They found that sodium butyrate induced autophagy and apoptosis in breast cancer cells and lymphoma[6]. Shahzad et al. showed that conjugated linoleic acid 
(CLA) as a free fatty acid prevented migration and proliferation of s SKOV-3 and A2780 cancer cell lines by inducing stress and autophagy[7].

GW9508 is a selective agonist for FFA1/GPR40 and a free fatty acid mimic. FFA1/GPR40 receptor is a G protein-coupled receptor, which can be stimulated by free fatty acids. GW9508 exhibited a selectivity of higher than 500-fold for GPR40 than others and attracted a stable in vitro profile with great bioavailability[8].

Several types of cell death pathways can occur in the cell, the most common of which is apoptosis. This canonical cell death can be triggered by multiple external and internal stimuli such as stress, drugs, and genetic factors. Another cell death pathway is autophagy, which is a lysosome-dependent pathway changing the content of the cell. The formation of double-membrane vesicles is the most obvious feature of autophagy in the cells associated with lysosomal degradation[9]. The autophagy process is a multistage path controlled by several Atg genes. PI3K and beclin 1 are necessary for the formation of primary autophagosome and accumulation of LC3-II as a marker of autophagy[9]. The mechanism of autophagy in cancer cells is not very clear and it has a dual application in tumor cells depending on conditions. Previous studies demonstrated that stress causes cell death including apoptosis and autophagy and leads to activation of AMPK and suppressor of mTOR[10,11].

The present study aimed to determine whether GW9508 treatment induced oxidative stress and autophagy in HT-29 cells.

\section{Experimental Procedures}

\section{Cell culture}

HT-29 cell lines were purchased from the Pastor Institute (Iran). The cells were cultured in Dulbecco's modified eagle medium (DMEM, Gibco, USA) supplemented with $10 \%$ fetal bovine serum (FBS, Gibco, USA), and penicillin/streptomycin $(100 \mathrm{U} / \mathrm{mL}, 100 \mu \mathrm{g} / \mathrm{mL})$ at $37^{\circ} \mathrm{C}$ and $5 \% \mathrm{CO} 2$ in an incubator (Sina, Iran).

\section{Fibrin gel preparation}

To produce fibrin gel, $3 \mathrm{mg}$ of fibrinogen (Sigma, USA) was gradually dissolved in $1 \mathrm{ml}$ M199 medium (Sigma, USA), supplemented with $15 \%$ FBS, and added to a 24 -well plate. Then, $30 \mu$ of thrombin (Sigma, USA) with a concentration of $120 \mathrm{U} / \mathrm{ml}$ was added to each well. To form jelly texture, the plate was incubated at $37^{\circ} \mathrm{C}$ for $2 \mathrm{~h}$.

\section{Electron microscopy}

HT-29 cells cultured in fibrin gel were washed by PBS and fixed with $2.5 \%$ glutaraldehyde for $2 \mathrm{~h}$. The samples were washed twice with PBS and dehydrated with ascending alcohol sequence $(30,50,70,80$, 
90, and 100\%). Each sample was dried and covered using gold powder and imaging was performed by an electron microscope (SEM, LEO. 1455VP, Germany).

\section{Cell viability}

The colorectal adenocarcinoma HT-29 cells were cultured at $10 \times 10^{3}$ cells/well in a 96 -well culture plate. The cells were then treated with concentrations of $50,100,200$, and $500 \mu \mathrm{g} / \mathrm{ml}$ of GW9508 for 1,3 , and 5 days. Then, MTT solution (3-(4, 5-dimethylthiazol- 2-yl)-2, 5-diphenyl tetrazolium bromide in DMEM) was added to each well at a concentration of $0.5 \mathrm{mM}$, and the cells were incubated for $3 \mathrm{~h}$ at $37^{\circ} \mathrm{C}$ to form MTT tetrazolium crystals. Next, the MTT solution was removed, the crystals were dissolved with Dimethyl sulfoxide (DMSO) and their absorbance was measured at $570 \mathrm{~nm}$ by an ELISA reader (FAX STAT, USA).

\section{Acridine orange/ethidium bromide (AO/EB) staining}

HT-29 Cells were stained with acridine orange/ethidium bromide at a concentration of $100 \mu \mathrm{g} / \mathrm{mL}(1: 1)$ for 5 min and observed using a fluorescence microscope (Olympus, Japan). In AO/EB stained cells, the live and apoptotic cells became green $(510-530 \mathrm{~nm})$ and red $(650 \mathrm{~nm})$ fluorescence, respectively. Briefly, the cells were cultured at a concentration of $50 \times 10^{3}$ cells/well fibrin gel in a 24-well culture plate and treated with IC50 concentration of GW9508 for 1 day. The cells were then washed by PBS and stained with AO/EB. The untreated cells were considered as a control group.

\section{Monodansylcadaverine (MDC) staining for autolysosomes}

HT-29 cells were cultured at a concentration of $50 \times 10^{3}$ cells/well fibrin gel in a 24-well culture plate and treated with IC50 concentration of GW9508 for 1 day. Then, the cells were stained with a $50 \mu \mathrm{M}$ concentration of MDC (Sigma, USA) for $45 \mathrm{~min}$ at $37^{\circ} \mathrm{C}$. The cells were then rinsed with PBS three times and observed using a fluorescence microscope (Olympus, Japan).

\section{Real-time quantitative PCR}

After treatments of HT-29 cells with IC50 concentration of GW9508 in a 6-well plate, RNA was extracted using RNX (Sinaclon, Iran), of which $300 \mathrm{ng}$ was used to synthesize cDNA (Sinaclon, Iran). Markers mRNA level was measured by using RealQ Plus 2x Master Mix Green (ampliqon) and the sequence of the primes are including BAX (F) GCTGGACATTGGACTTCCTC, BAX (R) ACCACTGTGACCTGCTCCA, BAD (F) CGGAGGATGAGTGACGAGTT, BAD (R) CCACCAGGACTGGAAGACTC, BCL-2 (F) GATGGGATCGTTGCCTTATGC, BCL-2 (R) CCTTGGCATGAGATGCAGGA, P53 (F) GGAGGGGCGATAAATACC, P53 (R) AACTGTAACTCCTCAGGCAGGC, Beclin-1 (F) ATGGAGGGGTCTAAGGCG, Beclin-1 (R) TGGGCTGTGGTAAGTAATG, Atg5 (F) GGACCTTCTACACTGTCCATCC, Atg5 (R) TGTCATTCTGCAGTCCCATC, LC3 (F) GATAATCAGACGGCGCTTGC, LC3 (R) ACTTCGGAGATGGGAGTGGA, GAPDH (F) GCAAGAGCACAAGAGGAAGA, GAPDH (R) ACTGTGAGGAGGGGAGATTC. The cDNA was amplified in 
duplicate by qRT-PCR with the conditions: $95^{\circ} \mathrm{C}$ for $15 \mathrm{~min}, 40$ cycles of $\left(30 \mathrm{~s}\right.$ at $95^{\circ} \mathrm{C}, 30 \mathrm{~s}$ at $48^{\circ} \mathrm{C}$, and $30 \mathrm{~s}$ at $72^{\circ} \mathrm{C}$ ) for $30 \mathrm{~s}$, and $55^{\circ} \mathrm{C}$ for $30 \mathrm{~s}$.

\section{Western blotting}

Protein isolation was carried out using RIPA lysis buffer. The protein concentration was measured by BCA Protein Assay Kit (Beyotime). Then, $10 \mu \mathrm{g}$ of each sample was loaded on SDS-polyacrylamide gel electrophoresis and transferred to a nitrocellulose membrane. The samples were blocked with $5 \%$ BSA in PBS containing $0.05 \%$ Tween-20. The membrane was incubated for $1.5 \mathrm{~h}$ at room temperature with anti p-AKT (1:500, Abcam), anti AKT (1:500, Abcam), anti p-mTOR (1:500, Abcam), anti mTOR (1:500, Abcam), anti AMPK (1:500, Abcam), anti P-AMPK (1:500, Abcam), and anti GAPDH (1:500, Abcam) followed by binding with an anti-rabbit secondary antibody anti-rabbit IgG-HRP (1:1000, Abcam). Ultimately, the bands were visualized by DAB solution (Sigma, Germany).

\section{Superoxide dismutase activity assay}

Superoxide dismutase (SOD) activity was assessed with a manual assay. The cell lysates from HT-29 cells in the treatment group (with IC50 concentration of GW9508) or control group (without treatment) were prepared and subjected to the assay following the Kono method[12]. This method was performed by measuring the inhibition of nitrotetrazolium reduction (NBT) in the presence of SOD at $560 \mathrm{~nm}$. In this method, superoxide anion is produced due to the spontaneous oxidation of hydroxylamine. The combination of NBT with superoxide reacts to produce formazan red. The superoxide dismutase enzyme in the sample reacts with superoxide and converts to hydrogen peroxide while preventing the formation of red color.

\section{Catalase activity assay}

Cell lysates were prepared from HT-29 cells in the treatment group with IC50 concentration of GW9508 or control group (without treatment) and subjected to the assay following the Koroluk method[13]. The hydrogen peroxide per time was reduced owing to the activity of the enzyme catalase. Ammonium molybdate formed a yellowish complex with hydrogen peroxide. In this method, the samples were exposed to $\mathrm{H} 2 \mathrm{O} 2$, and hydrogen was converted to water and oxygen by the enzyme in the sample. Residual hydrogen peroxide eventually produced a color compound with ammonium molybdate. The resulting color intensity was inversely related to the amount of enzyme activity.

\section{Molecular docking}

To predict the interaction of proteins involved in autophagy with GW9508, Molegro virtual docker (CLC Bio company, Aarhus, Denmark) was used along with g Molegro Virtual viewer V2.5 software. The 3D structures of proteins were recovered from the RCSB/PDB data bank and the 3D structure of ligand was retrieved from the Zinc database. The energy of EFL1 was recorded from the final output. To provide the proteins, we eliminated the metal ions, water molecules, solvent molecules, and fixed the side chain. 
Molecular docking was performed in Surflex-Dock Geom mode. The total scores were considered as a firm interaction when the value was more than 5 .

\section{Statistical analysis}

The experiments were carried out in triplicate and the data were displayed as mean \pm standard deviation (SD). The results were analyzed by one-way ANOVA. Also, $\mathrm{P}<0.05$ was considered statistically significant. The data were managed by SPSS version 16.0.

\section{Results}

\section{SEM observations of fibrin gel}

The SEM images of the fibrin scaffold are exhibited in Fig. $1 \mathrm{It}$ is observed that the scaffold produced a uniform, regular porous, and fibrous gel with interconnectivity. Also, Fig.1b indicated photographs taken from HT-29 cells in the fibrin gel after drying. The SEM photographs showed a suitable cell attachment and perfect integrity between the cells and fibrin gel. These results demonstrated that the HT-29 were entirely penetrated in the hydrogel and proliferated normally (Fig.1).

\section{Inhibition of the cell viability by GW9508 in HT-29 cells}

We investigated the effects of GW9508 treatment on HT-29 cell viability and proliferation by MTT assay. GW9508 significantly reduced the viability in HT-29 cells in a dose- and time-dependent method. The lowest concentration of GW9508 significantly reducing the viability was $50 \mu \mathrm{g} / \mathrm{ml}$ after $24 \mathrm{~h}$ (Fig. 2). At the 100 and $200 \mu \mathrm{g} / \mathrm{ml}$ concentration of GW9508, the presence of viability relative to control cells (untreated cells, $100 \%$ ) was approximately $81.10 \%$ and $67.97 \%$ after $24 \mathrm{~h}$, respectively. We also assessed HT-29 cells for their change at concentrations between $50-500 \mu \mathrm{g} / \mathrm{ml}$. No reduction was recognized in HT29 viability when the cells were treated whit concentrations of 50 and $100 \mu \mathrm{g} / \mathrm{ml}$ of GW9508. GW9508 decreased the viability of HT-29 cells at an IC50 of $500 \mu \mathrm{g} / \mathrm{ml}$. Also, the results revealed that the cell viability was time-dependent. Hence, the viability in the cells treated with IC50 concentration of GW9508 decreased to $51,10.6$, and $6.1 \%$ after 1,3 , and 5 days, respectively (Fig.2a, b).

\section{Accumulation of autolysosomes}

To investigate whether GW9508 can induce autophagy, we evaluated the formation of autolysosomes. For this purpose, DMC staining was used to detect autolysosomes. The treated cells with an IC50 concentration of GW9508 exhibited a plentiful increase in the number of vacuoles (as fluorescent dots) compared to control samples. This emphasized that GW9508 induced the formation of autolysosomes (Fig 2c, d). Also, AO/EB emits orange fluorescence in vesicles and shiny green in the cytoplasm. GW9508 $(500 \mu \mathrm{g} / \mathrm{ml})$ increased the accumulation of acidic vesicular (orange dots in the cells) in HT-29 cells compared to the control samples (no orange dots) (Fig1g, h).

GW9508 induced autophagy in HT-29 cells 
To further assess induction autophagy by GW9508 in HT-29 cells, the expression of LC3 was evaluated. LC3 is an autophagosome-related element and is extensively applied as an autophagic marker. A

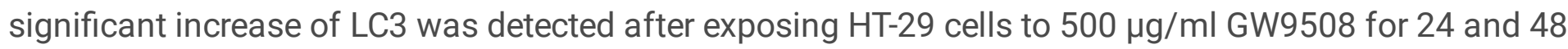
h. We also investigated the expression of Beclin-1 and Atg 5 as essential genes in autophagy and the formation of the autophagosome. qRT-PCR data indicated that the cells treated by GW9508 significantly increased expression of Beclin-1 and Atg5 in HT-29 cells compared to the control cells (Fig.2e). The expression of these markers suggested that GW9508 induced autophagy in HT-29 cells. The levels of expression increased in a time-dependent manner as the expression of genes in $48 \mathrm{~h}$ was mostly significantly more than $24 \mathrm{~h}$.

\section{Western blotting analysis}

To investigate the molecular mechanisms involved in cell cytotoxicity of WG9508 to the cells, we analyzed the expression of autophagic-related genes such as mTOR, AMPK, and AKT. As detected in Figure 3, the P-AMPK protein was upregulated, and P-mTOR and P-AKT proteins were downregulated by WG9508 treatment in cells. With the decrease in P-mTOR and P-AKT activation, the increase in autophagy was more evident. These results are consistent with the other changes from the qRT-PCR.

\section{Effects of WG9508 on the activity of antioxidative enzymes}

We investigated whether WG9508 lead to an increase in the activity of antioxidative enzymes. The activity of catalase and SOD were assessed to assess whether WG9508 changes the activity of antioxidative enzymes. The activity of both enzymes (catalase and SOD) was significantly increased in WG9508 treatment cells compared to the control cells (1.254 for SOD and .338 for catalase) (Fig. 4a). The data indicated that WG9508 increased the antioxidative potential of HT-29 cells.

\section{Molecular docking results}

We estimated the molecular interactions between GW9805 and some important administrative proteins, including mTOR, AMPK, AKT, catalase, and SOD through molecular docking. As exhibited in Fig. $3 \mathrm{~b}$ and 4b. and Table 1, the proteins had moderate RMSD $<2$ and a total score of $>5$ representing possible interactions within GW9805 and these proteins. GW9805 can induce autophagy and oxidative stress via primary interaction with autophagic and redox proteins. Our results indicated that GW9805 can interact with autophagic and redox proteins. Moreover, the results showed the hydrogen and steric bonds between GW9805 and proteins.

Theoretically, GW9805 was bound to AMKP via the formation of steric and hydrogen bonds at Tyr198, Ser199, Val202, Leu212, Glu168, and Asp166 (Fig. 3b). GW9805 was bound AKT via the formation of steric and hydrogen bonds at Glu288, Ala230, $\mathrm{HOH} 642$, $\mathrm{HOH} 795, \mathrm{HOH} 796, \mathrm{HOH} 726$, Asn279, Glu278, and Glu234 (Fig. 3b). GW9805 was bound to mTOR via the creation of steric and hydrogen bond at Gln85, Arg2036, Met2024, Glu2025, His2028, HOH2304, and Glu2032 (Fig. 3b). GW9805 was bound to catalase through the formation of steric and hydrogen bonds at Arg365, Leu366, His364, Pro368, Pro391, and 
His364 (Fig. 4b). Moreover, GW9805 was bound to SOD through the formation of steric and hydrogen bonds at Val148, Val7, and Asn53 (Fig. 4b).

\section{Discussion}

The effects of WG9508, free fatty acids, and fiber diet, in arresting and managing cancer are not exactly appreciated. Here, we indicate that WG9508 induced autophagy and enzymes involved in oxidative stress in HT-29 cells in vitro in line with other studies.

To more confirm our conclusions, a western blot was performed determining proteins associated with autophagy issues. Our findings for GW9508-treated HT-29 cells exhibited an increased expression of PAMPK and decreased P-mTOR and P-AKT proteins in treated cells, compared to the control cells. A decrease of P-mTOR and P-AKT proteins in cancer cells has been correlated with repressed growth and proliferation. We found that autophagy was induced in HT-29 based on high expression of Beclin-1, LC3, and suppression of expression of mTOR.

AKT is the main signaling pathway essentially transmitting mitogen and growth factors. Besides, AKT inhibits BAD protein via phosphorylation and represses induced apoptosis[10, 14].

To investigate whether autophagy or apoptosis was the main reason for cell death, we examined the apoptotic and autophagic markers. Moreover, we assessed the effect of GW9508 on decided enzymes included in cellular stress signaling. We concluded that WG9508 increased the level of catalase and SOD in HT-29 cells. Similar to our results, autophagy associated with oxidative stress has been reported in treatment in other studies[15-17]. Autophagy is a process caused by starvation, stress, and hypoxia, which can also cause cell death [18]. Tang et al. for the first time reported that short-chain fatty acids induce autophagy in colorectal cancer cells [19]. In the present study, we indicated that WG9508 has a dose-dependent function and induced autophagy at high doses $(500 \mu \mathrm{g} / \mathrm{ml})$. We also registered significant differences in the responses of the A549, HeLa, and HT-29 cells to WG9508 treatment. We also revealed the inhibition of HT-29 cell proliferation and induction of autophagy at a much higher concentration than others (not shown by the data).

Autophagy is an intricate process cross-talking with other pathways such as apoptosis. Autophagy may cause inhibition of apoptosis and expedite apoptosis. It may also associate with apoptosis to induce cell death[20]. BCL family members can be regarded as a double regulator for autophagy and apoptosis. The BCL-2 protein play an anti-apoptotic factor. Bax is considered as a pro-apoptotic factor releasing cytochrome $\mathrm{C}$. Autophagy may be suppressed by interacting BCL-2 with beclin1/PI3K pathway. While in stressful circumstances, BCL-2 is inhibited and the beclin 1/PI3K pathway is activated following autophagy $[15,21]$.

However, the definite molecular mechanisms inducing apoptosis or autophagy remain unclear. Since GW9508 treatment induces both apoptosis and autophagy, GW9508 would likely have its optimal effects (most anti-tumorigenic) when paired with an autophagy inhibitor. Our results indicated that GW9508 
treatment induces both apoptosis and autophagy in HT-29 cells. Nevertheless, no animal models study has been reported so far in this regard. Also, the reason for the possible variation in study outcomes is not apparent. Thus, it is important to pay attention to the concentration of GW9508 as an anti-cancer drug for treatment.

Also, free fatty acids induced autophagy associated with ROS production leading to activation of AMPK and mTOR inhibition [22]. It was suggested that stress may involve in crosstalk with the AMPK/mTOR signaling [23]. Hence, discovering the details of the cellular mechanism of action GW9508 can be helpful for drug development.

GW9508 exhibits a tremendous affinity for the receptor GPR40. Though, it also stimulates GPR120 to a secondary degree [8]. Therefore, GPR120 could be effective for cell viability appearing at higher concentrations. Since GW9508 leads to cell death and inhibition of cell proliferation, more examinations are demanded to receive responses. To explain mediating receptors, our results uncover a different perspective in phases of clinical examinations regarding the potential advantage of GW9508 in therapeutic approaches for cancer therapy.

Here, for the first time, we demonstrated that a high concentration of GW9508 as a small molecule plays a significant role to induce autophagy associated with oxidative stress in colorectal cells in a dosedependent method. Also, the significant increase in apoptotic markers against GW9508 suggests the possible inclusion of both apoptosis and autophagy processes. These results are in agreement with other studies reporting directing autophagy as a therapeutic strategy in colorectal cancer.

\section{Abbreviations}

The abbreviations used are: GPR40, G-coupled Protein Receptor 40; HT-29, human colorectal cancer cell line; SOD, Superoxide dismutase; CLA, conjugated linoleic acid.

\section{Declarations}

\section{Data availability}

All data are contained within this article and provided as supporting data.

\section{Acknowledgments}

We thank Shahid Chamran University for its supporting.

\section{Author contributions}

E. H. designed and developed the experiments analyzed data; B. R. interpreted the data and edited the manuscript; A. SH. assayed the enzyme activities. 


\section{Funding}

This study is supported by Shahid Chamran University of Ahvaz, grant number: 1399.

\section{Conflicts of interest}

The authors have declared that no conflict of interest exists.

\section{References}

1. Retraction (2019) APRIL Induces Tumorigenesis and Metastasis of Colorectal Cancer Cells via Activation of the PI3K/Akt Pathway. PloS one 14:e0222525

2. Slattery ML, Mullany LE, Sakoda LC, Wolff RK, Samowitz WS, Herrick JS (2018) Dysregulated genes and miRNAs in the apoptosis pathway in colorectal cancer patients. Apoptosis 23:237-250

3. Zhou Y, Bian S, Zhou X, Cui Y, Wang W, Wen L, Guo L, Fu W, Tang F (2020) Single-Cell Multiomics Sequencing Reveals Prevalent Genomic Alterations in Tumor Stromal Cells of Human Colorectal Cancer. Cancer cell 38:818-828 e815

4. Li P, Shan B, Jia K, Hu F, Xiao Y, Zheng J, Gao YT, Wang H, Gao Y (2020) Plasma omega-3 polyunsaturated fatty acids and recurrence of endometrial cancer. BMC Cancer 20:576

5. Zoni E, Minoli M, Bovet C, Wehrhan A, Piscuoglio S, Ng CKY, Gray PC, Spahn M, Thalmann GN, Kruithof-de Julio M (2019) Preoperative plasma fatty acid metabolites inform risk of prostate cancer progression and may be used for personalized patient stratification. BMC Cancer 19:1216

6. Fauser JK, Prisciandaro LD, Cummins AG, Howarth GS (2011) Fatty acids as potential adjunctive colorectal chemotherapeutic agents. Cancer Biol Ther 11:724-731

7. Shahzad MMK, Felder M, Ludwig K, Van Galder HR, Anderson ML, Kim J, Cook ME, Kapur AK, Patankar MS (2018) Trans10,cis12 conjugated linoleic acid inhibits proliferation and migration of ovarian cancer cells by inducing ER stress, autophagy, and modulation of Src. PloS one 13:e0189524

8. Liu Z, Hopkins MM, Zhang Z, Quisenberry CB, Fix LC, Galvan BM, Meier KE (2015) Omega-3 fatty acids and other FFA4 agonists inhibit growth factor signaling in human prostate cancer cells. $J$ Pharmacol Exp Ther 352:380-394

9. Poillet-Perez L, Xie X, Zhan L, Yang Y, Sharp DW, Hu ZS, Su X, Maganti A, Jiang C, Lu W, Zheng H, Bosenberg MW, Mehnert JM, Guo JY, Lattime E, Rabinowitz JD, White E (2019) Author Correction: Autophagy maintains tumour growth through circulating arginine. Nature 565:E3

10. Duan L, Calhoun S, Shim D, Perez RE, Blatter LA, Maki CG (2021) Fatty acid oxidation and autophagy promote endoxifen resistance and counter the effect of AKT inhibition in ER-positive breast cancer cells. Journal of molecular cell biology

11. Saber MM, Al-Mahallawi AM, Nassar NN, Stork B, Shouman SA (2018) Targeting colorectal cancer cell metabolism through development of cisplatin and metformin nano-cubosomes. BMC Cancer $18: 822$ 
12. Kono Y (1978) Generation of superoxide radical during autoxidation of hydroxylamine and an assay for superoxide dismutase. Arch Biochem Biophys 186:189-195

13. Koroliuk MA, Ivanova LI, Maiorova IG, Tokarev VE (1988) [A method of determining catalase activity]. Laboratornoe delo:16-19

14. Ferreira-Marques M, Carvalho A, Cavadas C, Aveleira CA (2021) PI3K/AKT/MTOR and ERK1/2-MAPK signaling pathways are involved in autophagy stimulation induced by caloric restriction or caloric restriction mimetics in cortical neurons. Aging 13

15. Zhang J, Yi M, Zha L, Chen S, Li Z, Li C, Gong M, Deng H, Chu X, Chen J, Zhang Z, Mao L, Sun S (2016) Sodium Butyrate Induces Endoplasmic Reticulum Stress and Autophagy in Colorectal Cells: Implications for Apoptosis. PloS one 11:e0147218

16. Ashrafizadeh M, Tavakol S, Ahmadi Z, Roomiani S, Mohammadinejad R, Samarghandian S (2020) Therapeutic effects of kaempferol affecting autophagy and endoplasmic reticulum stress. Phytother Res 34:911-923

17. Jeong SJ, Stitham J, Evans TD, Zhang X, Rodriguez-Velez A, Yeh YS, Tao J, Takabatake K, Epelman S, Lodhi IJ, Schilling JD, DeBosch BJ, Diwan A, Razani B (2021) Trehalose causes low-grade lysosomal stress to activate TFEB and the autophagy-lysosome biogenesis response. Autophagy:113

18. Chou HY, Lee YT, Lin YJ, Wen JK, Peng WH, Hsieh PL, Lin SY, Hung CC, Chen GC (2020) PTPN9mediated dephosphorylation of VTI1B promotes ATG16L1 precursor fusion and autophagosome formation. Autophagy:1-16

19. Tang Y, Chen Y, Jiang H, Nie D (2011) Short-chain fatty acids induced autophagy serves as an adaptive strategy for retarding mitochondria-mediated apoptotic cell death. Cell death differentiation 18:602-618

20. Liu J, Qin X, Ma W, Jia S, Zhang X, Yang X, Pan D, Jin F (2021) Corilagin induces apoptosis and autophagy in NRF2addicted U251 glioma cell line. Molecular medicine reports 23

21. Shao ZQ, Dou SS, Zhu JG, Wang HQ, Wang CM, Cheng BH, Bai B (2021) Apelin-13 inhibits apoptosis and excessive autophagy in cerebral ischemia/reperfusion injury. Neural regeneration research 16:1044-1051

22. Dong W, Liu G, Zhang K, Tan Y, Zou H, Yuan Y, Gu J, Song R, Zhu J, Liu Z (2021) Cadmium exposure induces rat proximal tubular cells injury via p62-dependent Nrf2 nucleus translocation mediated activation of AMPK/AKT/mTOR pathway. Ecotoxicol Environ Saf 214:112058

23. Kaushal GP, Chandrashekar K, Juncos LA (2019) Molecular Interactions Between Reactive Oxygen Species and Autophagy in Kidney Disease. International journal of molecular sciences 20

\section{Tables}


Table 1

Molecular interactions between GW9508 and human proteins.

\begin{tabular}{|c|c|c|c|c|}
\hline Protein & PDB(ID) & $\operatorname{RMSD}\left(\mathrm{A}^{\circ}\right)$ & $\begin{array}{l}\text { Total } \\
\text { Score }\end{array}$ & Hydrogen and Steric bonds \\
\hline AKT & 4GV1 & 1.462 & -172.444 & $\begin{array}{l}\text { Glu288, Ala230, } \mathrm{HOH} 642, \mathrm{HOH} 795, \mathrm{HOH} 796 \text {, } \\
\mathrm{HOH} 726 \text {, Asn279, Glu278, and Glu234 }\end{array}$ \\
\hline mTOR & $4 \mathrm{DRH}$ & 1.786 & -144.775 & $\begin{array}{l}\text { Gln85, Arg2036, Met2024, Glu2025, His2028, } \\
\mathrm{HOH} 2304 \text {, and Glu2032 }\end{array}$ \\
\hline AMPK & 3AQV & 0.825 & -145.817 & $\begin{array}{l}\text { Tyr198, Ser199, Val202, Leu212, Glu168, and } \\
\text { Asp166 }\end{array}$ \\
\hline SOD & $3 \mathrm{H} 2$ & 1.255 & -54.170 & Val148, Val7, and Asn53 \\
\hline Catalase & 1DGB & 0.578 & -230.729 & $\begin{array}{l}\text { Arg365, Leu366, His364, Pro368, Pro391, and } \\
\text { His364 }\end{array}$ \\
\hline
\end{tabular}

\section{Figures}
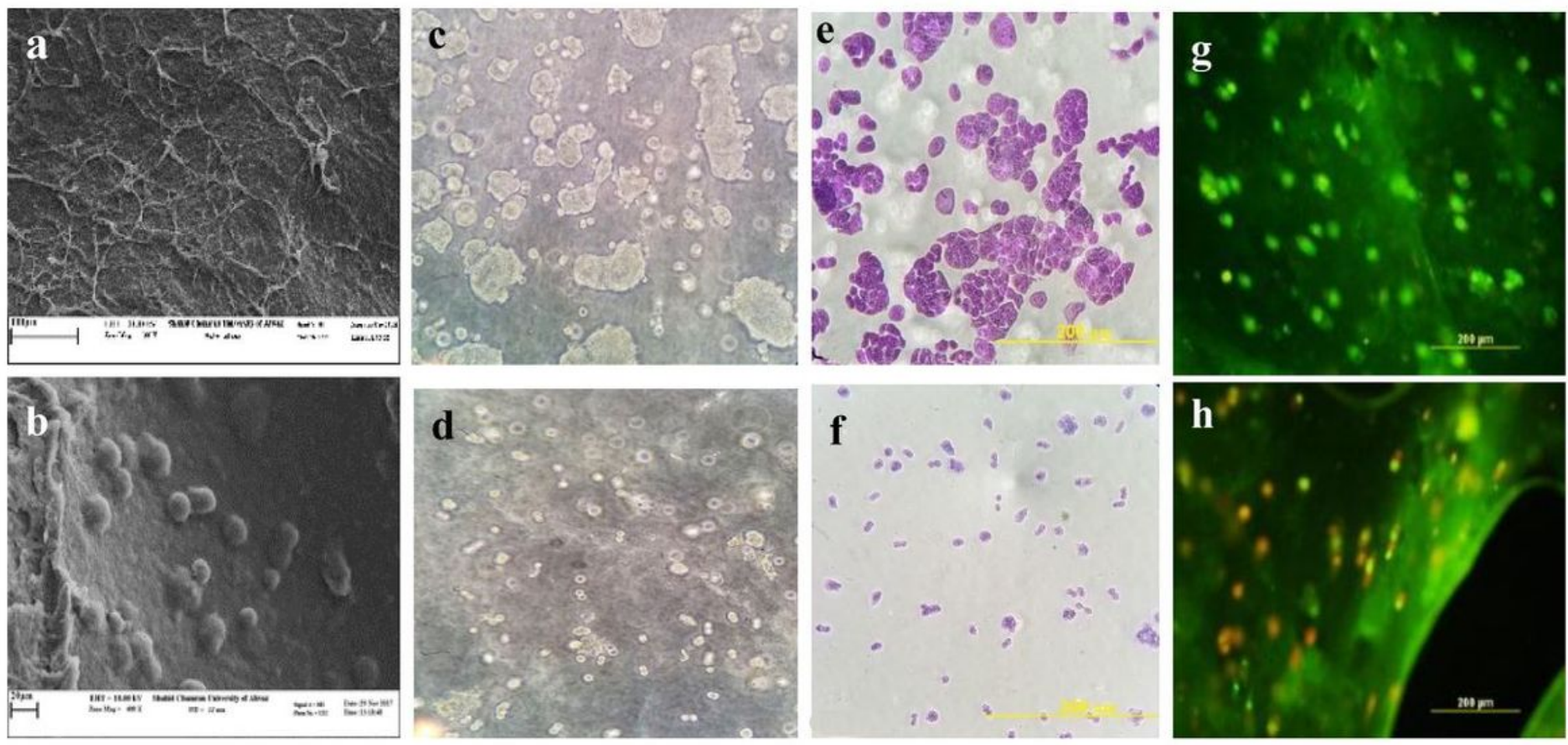

\section{Figure 1}

a SEM photographs as a 3D open porous and interconnected porosity and b HT-29 cells attached and spread in the fibrin gel. c The phase-contrast images of HT-29 cultured at control group in fibrin after $24 \mathrm{~h}$ and d The phase-contrast images of HT-29 in treated group with IC50 concentration of GW9508. magnification 20X. e Giemsa staining of HT-29 cultured at control group in fibrin after 24h. f Giemsa 
staining of treated group with IC50 concentration of GW9508. g AO/EtBr staining: control HT-29 cells exhibiting green normal nuclei. h AO/EtBr staining: GW9508 treated HT-29 cells exhibiting apoptotic cells with condensed orange nuclei.

$$
\text { =Day } 1 \text { =Day } 2 \text { =Day } 3
$$

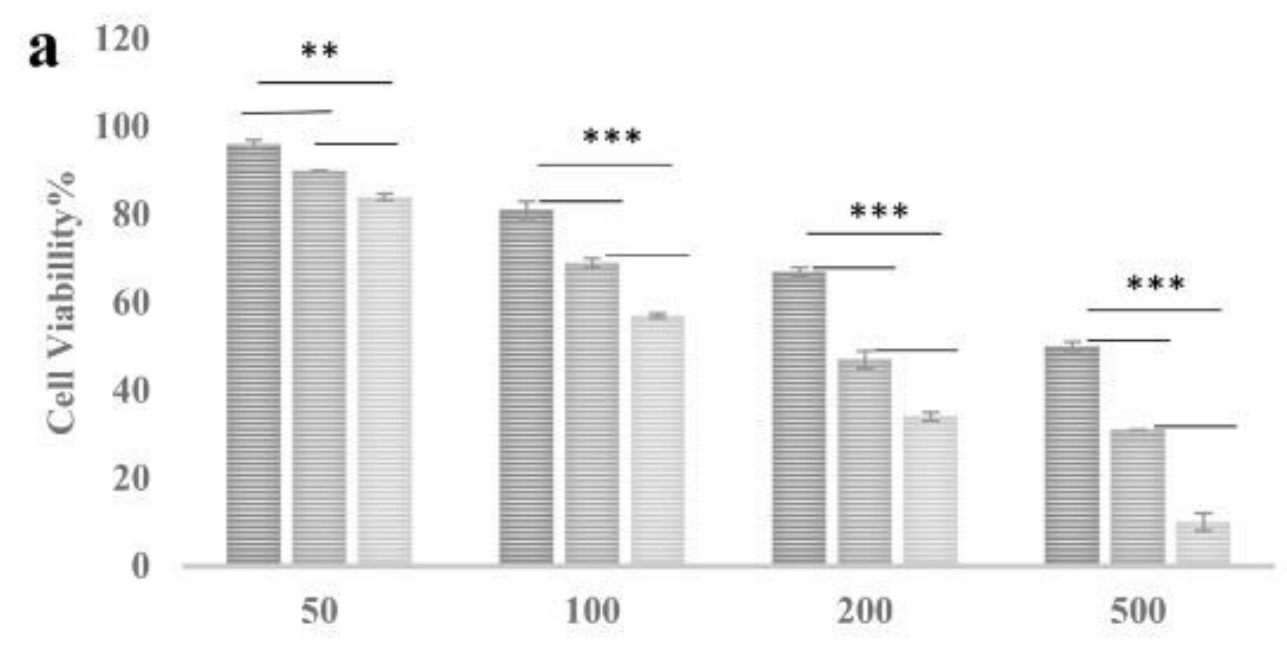

Concentration of GW9508 $\mu \mathrm{M}$
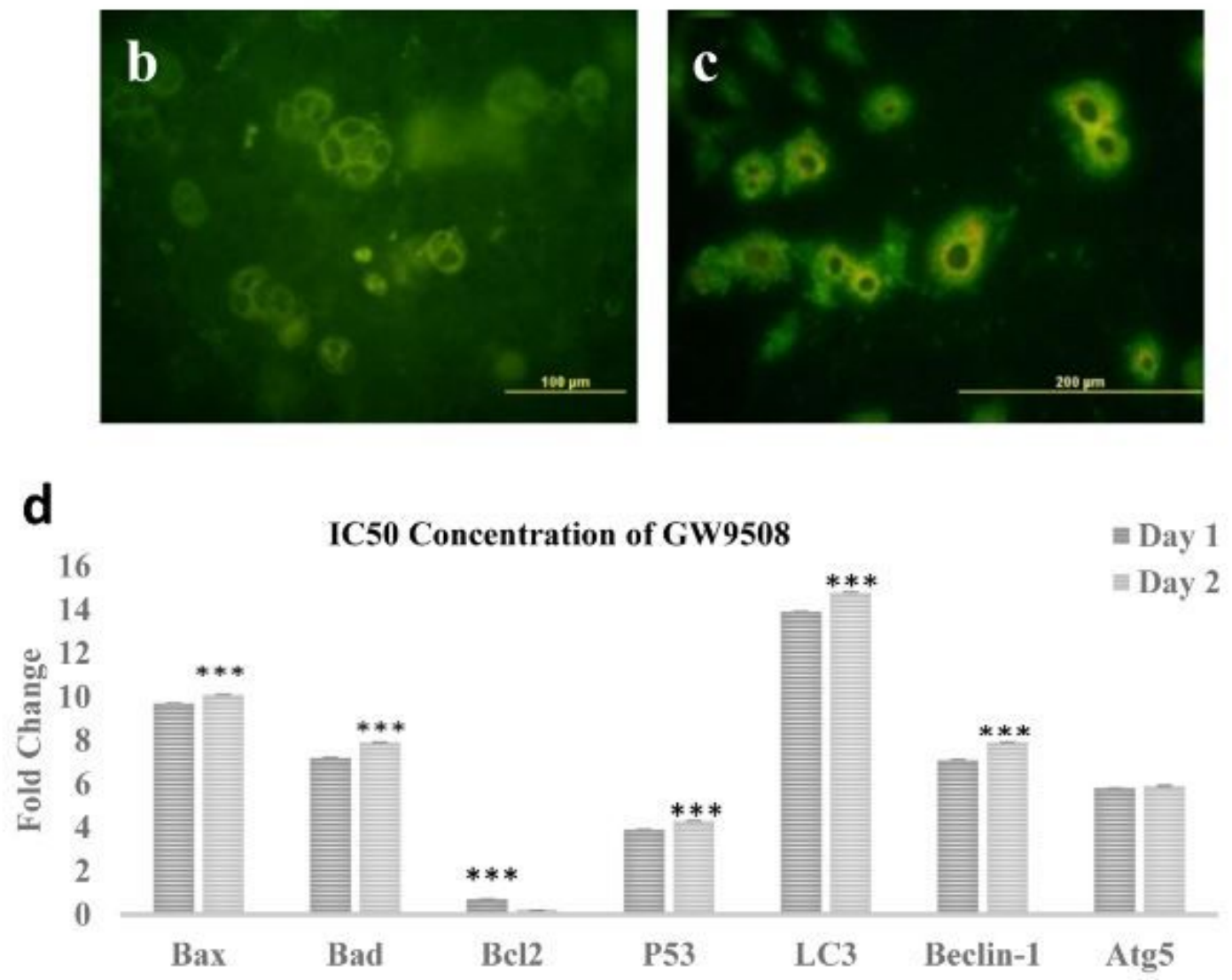

Figure 2

The viability of HT-29 treated with various concentrations of GW9508. MTT assay was used to evaluate the cell viability. a HT-29 cells were treated with $50,100,200$, and $500 \mu \mathrm{g} / \mathrm{ml}$ of GW9508 for 1,2 , and 3 
days and untreated cells considered as a control sample. ${ }^{*} \mathrm{P}<0.05$, ${ }^{* *} \mathrm{P}<0.01$, and ${ }^{* \star *} \mathrm{P}<0.001$. b MDC staining of HT-29 cells in control group. c MDC staining of HT-29 cells treated with IC50 concentration of GW9508. d qRT-PCR analyses of autophagic-related genes; LC3, Beclin-1, and Atg5 for HT29 cells when treated with GW9508 (IC50) for 1 and 2 days. The expressions of the markers were normalized to GAPDH.

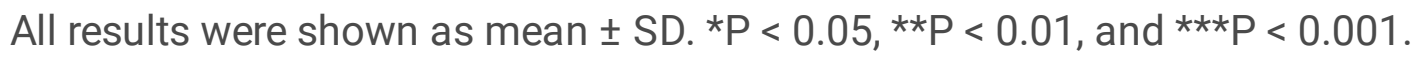

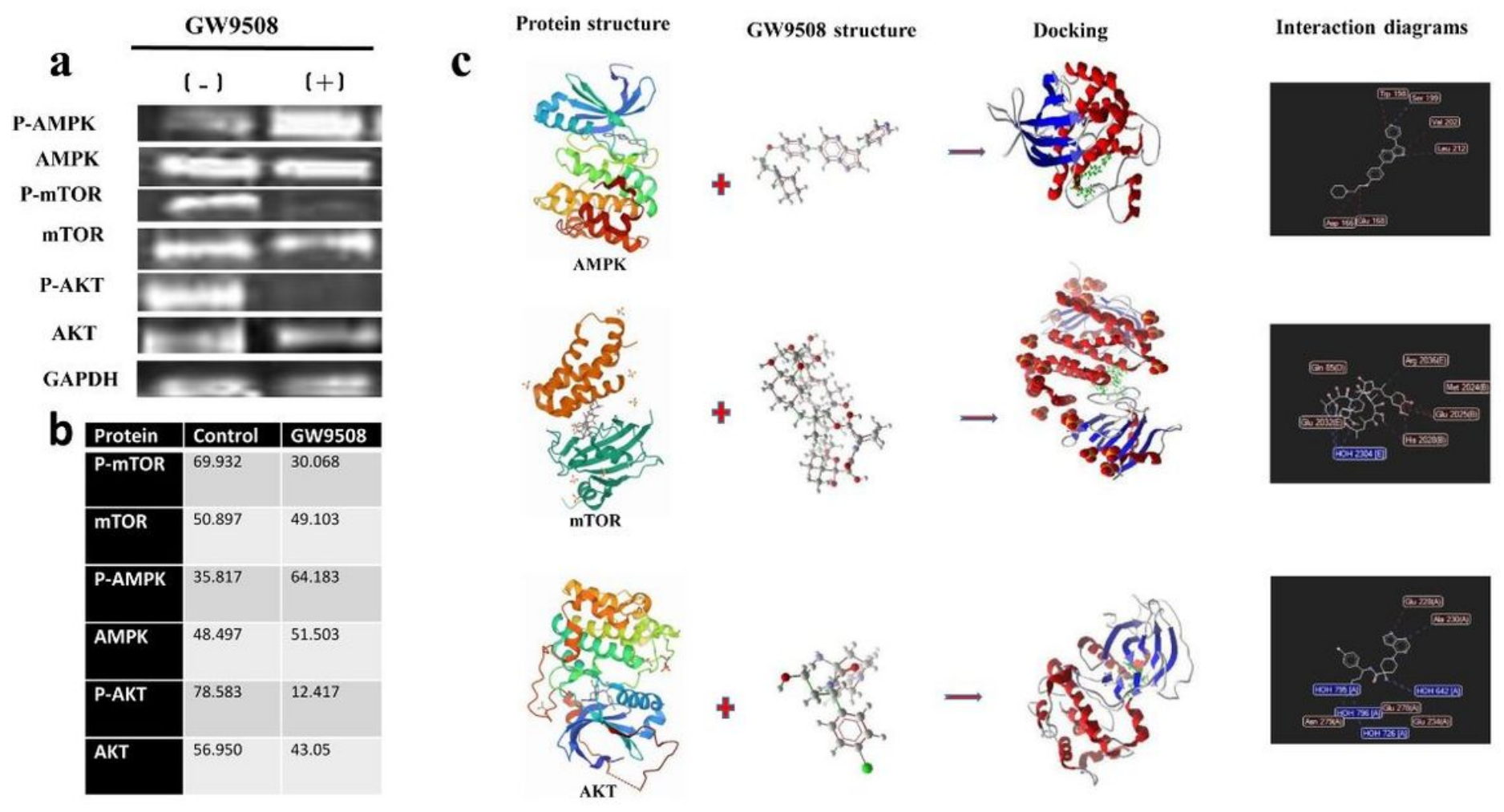

Figure 3

a The western blot considering the protein expressions of autophagic-related genes including $\mathrm{mTOR}$, AMPK, and AKT in HT-29 cells treated with the IC50 concentration of GW9508 for $24 \mathrm{~h}$. b Protein expression was quantified using Image $J$ software (Relative intensity percentage). c Molecular docking studies and interaction between GW9508 (green) and mTOR, AMPK, and AKT proteins. Red and blue dashed lines represent steric and hydrogen bonds, respectively. 
a

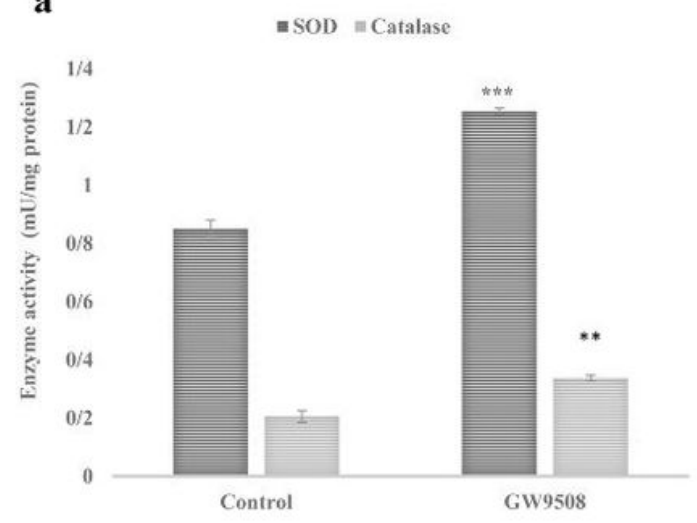

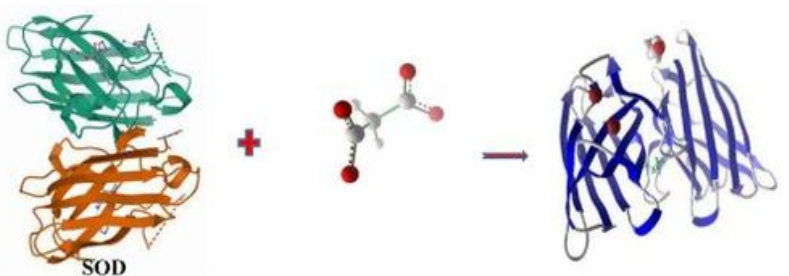
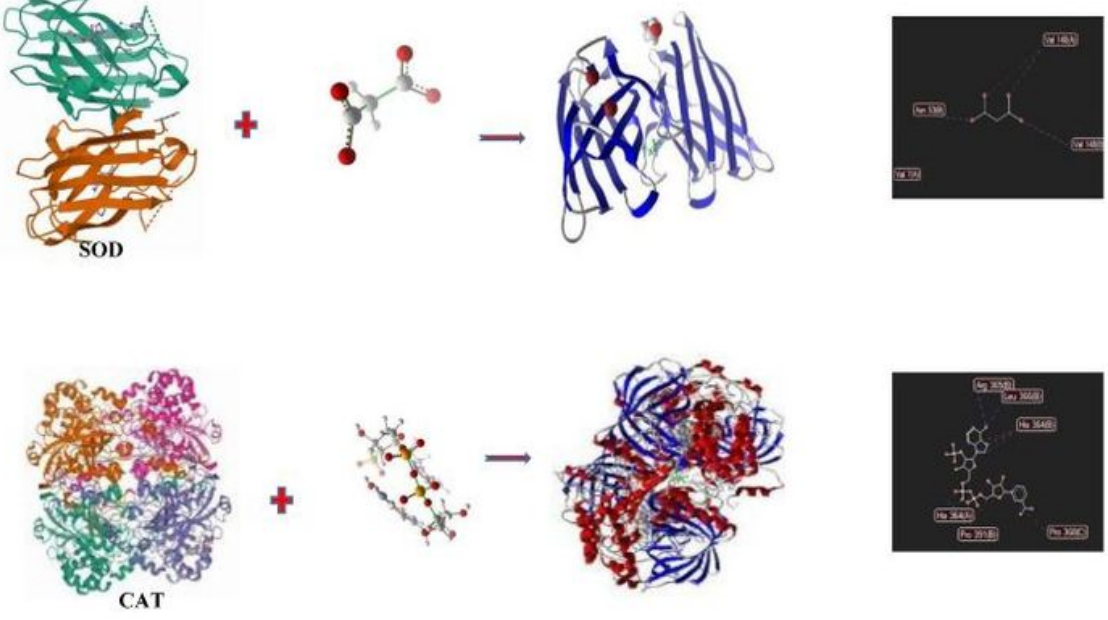

\section{Figure 4}

a GW9508 increased the antioxidative capacity of HT-29 cells. The activity of catalase and SOD in HT-29 cells was significantly increased by $500 \mu \mathrm{g} / \mathrm{ml}$ of GW9508 compared to the control. b Molecular docking studies, and interaction between GW9508 (green) and catalase and SOD proteins. Red and blue dashed lines represent steric and hydrogen bonds, respectively. 